\title{
RELAÇÕES QUALITATIVAS DE CONSUMO: OS SERVIÇOS DE HOTELARIA DIRECIONADOS AO PÚBLICO HOMOSSEXUAL.
}

\section{Qualitatives relations in consumption: the hotel services directed to homosexual public.}

\author{
Yákara Vasconcelos Pereira Leite ${ }^{1}$ \\ Valdemar Siqueira Filho ${ }^{2}$ \\ Juliana Pinheiro da Silva ${ }^{3}$
}

\section{Resumo}

O mercado destinado ao público homossexual possui um papel de destaque na população brasileira. Observando a lacuna de estudos nessa área, esta investigação se propõe a examinar o seguinte problema de pesquisa: Quais são as respostas emocionais destes consumidores entrevistados durante a experiência de consumo nos hotéis? As respostas emocionais são reações de qualidade de sentimento dos consumidores provocadas pelos estímulos do ambiente de serviços, caso sejam julgadas pelos clientes como sendo positivas essas respostas, pode-se alcançar a sua fidelidade. Este artigo tomou como base uma pesquisa qualitativa realizada com homossexuais residentes na cidade do Recife. Os resultados indicaram que, dentre as respostas emocionais mais memoráveis, a sensação de liberdade, privacidade, tranquilidade e paz (qualidade de sentimento), conforto e relaxamento (respostas fisiológicas) foram as que mais se destacaram. Desse modo, percebeu-se que a experiência de consumo dos homossexuais está intimamente relacionada com os estímulos dos canais sensoriais (visão, audição, olfato e tato) e com os sentimentos provocados pelo ambiente.

Palavras-chave: Turismo; Hotel; Experiência de Consumo; Consumidor gay.

\begin{abstract}
The GLS market has a role in the brazilian population. Observing the lack of study in this area, this research aims to examine the following investigation problem: What are the internal responses of the gay consumers interviewed during the consumer experience in hotels? The

\footnotetext{
${ }^{1}$ Doutoranda do Programa de Pós-Graduação em Administração da UFPE, docente da Universidade Federal Rural do Semi-Árido. E-mail: yakarav@ gmail.com, fone: 84.8723-4505.

${ }^{2}$ Doutor em Comunicação e Semiótica - PUC/SP, docente da Universidade Federal Rural do Semi-Árido UFERSA, E-mail: dhemah@uol.com.br.

${ }^{3}$ Graduada em Hotelaria pela UFPE.
} 
Relações qualitativas de consumo: os serviços de hotelaria direcionados ao público homossexual

de Yákara Vasconcelos Pereira Leite, Valdemar Siqueira Filho e Juliana Pinheiro da Silva

internal answers are the emotional reactions of consumers caused by services environments stimuli, if they are judged by customers as positive responses, their loyalty can be achieved. Seeking to discover the perspectives of respondents, a qualitative research was developed. The selection criterion of respondents considered the saturation of the categories that were formed during the collection and analysis, totalizing six homosexual males living in the city of Recife. The method of semi-structured interviews was used for data collection. The analysis was supported by the encryption of data considering the content of the speech, which contributed to the identification of categories that responded to the research question. The results indicated that among the most memorable internal responses, the feeling of freedom, privacy, tranquility and peace (emotional responses), comfort and relaxation (physiological responses) were the ones that stood out. Thus, it was noted that the consumer experience of homosexuals is closely related to the stimuli of the sensory channels (vision, hearing, smell and touch) and the feelings caused by the environment.

Keywords: Tourism, Hotel, Consumer Experience, Gay consumer.

\section{Resumen}

El mercado gay ha conquistado un espacio importante en la población brasileña. Tomando nota de la falta de investigación en esta área, esta investigación tiene como objetivo examinar el problema de investigación: ¿Cuáles son las respuestas emocionales de los consumidores encuestados en la experiencia de consumo en los hoteles? Las respuestas emocionales son reacciones de confianza del consumidor de calidad causada por los servicios de los estímulos ambientales, deben ser juzgadas por los clientes como las respuestas positivas y puede alcanzar su lealtad. Este artículo se basa en una investigación cualitativa con hombres gays que viven en la ciudad de Recife. Los resultados indicaron que entre las respuestas emocionales más memorables, la sensación de libertad, privacidad, tranquilidad y la paz (la calidad de la sensibilidad), la comodidad y la relajación (respuestas fisiológicas) fueron los más destacados. Por lo tanto, se señaló que la experiencia del consumidor de los homosexuales está estrechamente relacionada con los estímulos de los canales sensoriales (visión, audición, olfato y tacto) y con los sentimientos causados por el entorno. Palabras-clave: Turismo, Hotelería y experiencia del consumidor, consumidor gay.

\section{INTRODUÇÃO}


Relações qualitativas de consumo: os serviços de hotelaria direcionados ao público homossexual

de Yákara Vasconcelos Pereira Leite, Valdemar Siqueira Filho e Juliana Pinheiro da Silva

O turismo e a hotelaria têm se apresentado, nas últimas décadas, como uma das atividades que contribuíram positivamente para o crescimento econômico do Brasil. Devido à sua importância na geração de emprego e renda na sociedade, parece ser oportuno investigálos para compreender a sua dinâmica e organização a partir de uma perspectiva que articule o conceito de cultura brasileira (HOLANDA, 2006) e, como referência identificadora de consumidores, empresas da indústria hoteleira têm buscado, cada vez mais, a excelência na prestação dos serviços oferecidos. Por esse motivo, as organizações pertencentes a esse setor começaram a buscar tipos de clientes a quem elas possam fornecer seus produtos ou serviços com qualidade, de modo a estabelecer fidelidade (KOTLER, 2000). Objetivando satisfazer seus clientes, as empresas de serviços estão criando produtos mais personalizados e direcionados a determinados segmentos de mercado que estão atentos as propostas de não padronização dos serviços (MORAES, 2000). Entretanto, identificam de forma instrumental os traços que marcam a fidelização, sem uma reflexão dos traços culturais que marcam o consumidor.

Dentre os segmentos de mercado que mais têm procurado produtos e serviços personalizados, podemos apontar a cultura de consumo homossexual (KATES, 1998, 2002; NUNAN, 2003; PEÑAZOLA, 1996; PEREIRA; AYROSA; OJIMA, 2005) por ser considerada como "um dos segmentos que mais tem se projetado no cenário brasileiro" (PEREIRA; AYROSA; OJIMA, 2005, p. 1). Segundo Peñazola (1996), é provável que existam diferenças nos significados e no modo de como os produtos e serviços são utilizados entre homossexuais e heterossexuais, no entanto, "poucas pesquisas foram conduzidas para explorar as diferenças de atitudes e comportamentais entre os homossexuais" (NEWMAN; NELSON, 1996, p. 57).

Acredita-se que os elementos próprios do ambiente onde os serviços são realizados podem ser os fatores capazes de influenciar o consumo do público GLS em bares, restaurantes e hotéis. Bagozzi, Gopinath e Nyer (1999), por exemplo, fortalecem essa concepção ao afirmar que o ambiente de loja, como as músicas de fundo, marcas e iluminação devem ser administrados para produzir reações emocionais nos consumidores. Muitas empresas estão enfatizando mais os efeitos dos vários estímulos provocados pelo ambiente durante a experiência de consumo do cliente, por acreditarem na premissa de que as emoções geradas impulsionam as respostas de compra dos clientes (BAGOZZI; GOPINATH; NYER, 1999). Essa opinião também é compartilhada por Walkfield e Blodgett (1994), pois, do ponto de vista desses autores, nas empresas de serviços relacionadas ao lazer, dentre elas os hotéis, 
Relações qualitativas de consumo: os serviços de hotelaria direcionados ao público homossexual

de Yákara Vasconcelos Pereira Leite, Valdemar Siqueira Filho e Juliana Pinheiro da Silva

acredita-se que o consumo é induzido por motivos emocionais, identificando a questão das respostas individuais, ou seja, reações de sentimento de bem estar dos clientes.

Cabe aqui delimitar que este processo de indução é muito utilizado pela área de comunicação, mas pouco reconhecido como eficaz por vários autores usados nesta área, como Bakhtin, Morin, Serres, Pinheiro, Ferreira, por exemplo.

Diante disso, despertou-se o interesse de investigar a relação entre os elementos do ambiente e os aspectos apontados que supostamente influenciam o comportamento de consumo do público homossexual na indústria hoteleira. Assim, nossa pesquisa concentrou-se no modo como os homossexuais respondem aos vários elementos do ambiente dos hotéis, e como estas respostas orientam as ações deste segmento. Para tanto, consideraremos as ações de marketing estratégico e sua contribuição no desenvolvimento de estudos acadêmicos da área e, nesse sentido, propomos como problema de pesquisa estabelecer: As respostas que marcam os consumidores gays entrevistados durante a experiência de consumo nos hotéis podem orientar a área de hotelaria sobre o oferecimento de serviços mais qualificados.

\section{EXPERIÊNCIA DE CONSUMO}

Buscando esclarecer a questão desta pesquisa, identificamos uma crescente tendência em proporcionar experiências aos consumidores, principalmente, no setor dos serviços (BERRY; CARBONE; HAECKEL, 2002; PULLMAN; GROSS, 2003). Atualmente, o conceito de experiência no marketing implica o oferecimento de vivência mais atrativa para os consumidores. Por esse motivo, anteriormente o foco nas características funcionais e nos benefícios que os produtos proporcionam e a visão dos clientes como tomadores de decisão racional são algumas das principais especificidades do marketing tradicional, que estão dando lugar ao marketing experiencial, que enfoca as experiências do consumidor (SCHMITT, 2002). O resultado dessa transformação e da procura por experiências pelos clientes tem feito com que muitas empresas enfatizem as características que seus produtos e serviços podem oferecem, ressaltando a estimulação e os eventos memoráveis que o produto é capaz de produzir no consumo.

De acordo com Schmitt (2002, p.77), que é um dos maiores estudiosos dessa área, "marketing experiencial baseia-se na teoria e prática psicológica do cliente em si e no seu comportamento". Por esse motivo, o esqueleto do marketing experiencial é constituído por duas características: os modelos experienciais estratégicos (MEEs), que são o sentido, o sentimento, pensamento, ação e identificação, e os provedores de experiências, os ProExs, que 
Relações qualitativas de consumo: os serviços de hotelaria direcionados ao público homossexual

de Yákara Vasconcelos Pereira Leite, Valdemar Siqueira Filho e Juliana Pinheiro da Silva 256

são o espaço ambiental, as pessoas, a presença do produto, as co-marcas, as comunicações, a mídia eletrônica e a identidade visual e verbal (SCHMITT, 2002, p.83). Segundo o autor, os apelos experienciais raramente têm como fruto um único tipo de experiência. Muitos empreendimentos bem-sucedidos usam híbridos experienciais, ou seja, a combinação de dois ou mais modelos experienciais estratégicos, com a finalidade de aumentar seu apelo e aconselha ainda o mesmo autor: "o ideal é que os profissionais de marketing se empenhem de modo estratégico para criar experiências holisticamente integradas que possuam, ao mesmo tempo, qualidades de sensação, sentimento, pensamento, ação e relacionamento".

Parece recorrente nestas abordagens o problema básico desde o íncio do século passado com relação à teoria da comunicação que articulava de forma excludente emissor e receptor, sendo o primeiro agente do processo e cabendo ao segundo uma ação passiva e controlada. Recentemente tivemos, nas eleições no Brasil, novo exemplo da mídia apoiando claremente o candidato José Serra, e o poder de sugestão da mídia não impediu sua derrota. Assim, o problema desta abordagem está em uma interpretação dualística e excludente, sem reconhecer o caráter processual das relações em que o poder está na capacidade de compartilhamento de projetos coletivos.

Pine e Gilmore (1998, p. 97) advogam que os consumidores "indiscutivelmente desejam experiências" e, por esse motivo, as experiências são consideradas como o próximo degrau no que denominam "progressão do valor econômico". Essa progressão começa com a aquisição de commodities por parte dos consumidores e, a partir do avanço da economia industrial, o mercado se volta para o consumo de produtos manufaturados. Com o tempo, a economia de serviços decola e, por consequência, substitui os produtos industrializados. Foi então que, a partir dos anos 90, os serviços começaram a ser trocados por experiências de consumo (PINE; GILMORE, 1998).

As experiências foram definidas por Schmitt (2002, p. 71) como "acontecimentos individuais que ocorrem como resposta a algum estímulo". Segundo Schmitt e Siminson (2002), as experiências sensoriais da empresa contribuem para a identidade organizacional, uma vez que, as experiências não são na sua maioria espontâneas, e sim induzidas; os estímulos gerados pelas empresas podem fazer com que os consumidores as vejam como simpáticas, admiradas, interessantes, etc.

Percebe-se no uso do termo "estímulo" ainda uma abordagem behaviorista sobre as relações, ancorada na armadilha teórica entre pares excludentes, nesta, um é o centro e o outro é o periférico. Por outro lado, se a sociedade desde o fim do século passado é abordada como sendo pós-industrial, na qual a informação é um valor de múltiplos sentidos, não cabe tratá-la 
Relações qualitativas de consumo: os serviços de hotelaria direcionados ao público homossexual

de Yákara Vasconcelos Pereira Leite, Valdemar Siqueira Filho e Juliana Pinheiro da Silva 257

unilateralemente no espaço da cultura, onde os valores nascem dos processos de negociação, como sendo propriedade de todos. As exeperiências devem ser propostas e vividas e não testadas como na lógica behaviorista, em que respostas são esperadas para avaliar resultados. Mas essa é uma crítica que fazemos ao olhar que o markeitng lança sobre as experiências do consumo, desconsiderando a importância da casualidade na construção dos sentidos dos consumos vividos.

De qualquer forma, sabemos que segundo estas teorias, as experiências podem ser classificadas em duas dimensões, de acordo com Pine e Gilmore (1998). A primeira dimensão corresponde à participação do consumidor, que em uma escala oscila da participação ativa, em que os consumidores assumem papéis efetivos, à participação passiva, na qual os consumidores não interferem no desempenho da experiência, são como simples observadores (PINE; GILMORE, 1998). As experiências são, portanto, "pessoais, envolvendo reações subjetivas, emoções privadas e imagens mentais" (DUBE; LE BEL; SEARS, 2003, p. 126), e podem, assim, ser definidas como algo estimulador e inesquecível. Parece-nos, entretanto, um equívico tratar as experiênicas subjetivas como sendo passivas, pois as mesmas, por um lado, remetem a uma ação externa que não poderia gerenciar o inconsciente de outrem, nem tão pouco tratar a subjetividade como oposto da ação, já que ela participa ativamente de nossas realizações. Edgar Morin (2006) afirma que o problema de algumas abordagens sobre a subjetividade está na afirmação da morte do sujeito.

Existem, no entanto, algumas diferenças entre as experiências de consumo. Addis e Holbrook (2001, p.57) sugerem que as diferenças entre as experiências de consumo possam ser explicadas pela ênfase de subjetividade e objetividade que o produto apresenta como característica principal. Os produtos possuem certas características objetivas, tais como a cor, formato, peso e outras, enquanto os consumidores incorporam uma "personalidade equipada por vários tipos de respostas subjetivas", como sentimentos, emoções, crenças, etc. A diferença entre as experiências de consumo é, então, determinada pela relevância (ou) das características objetivas ou das respostas subjetivas.

O produto é considerado utilitário por natureza quando o indivíduo o utiliza devido às suas características funcionais, como, por exemplo, o uso de uma impressora. O consumo utilitário, ou seja, o uso de produtos utilitários está intimamente ligado à funcionalidade do produto; os sentimentos pessoais, todavia, não interferem no funcionamento do produto. Se, por outro lado, a experiência de consumo apresenta uma ênfase maior na resposta subjetiva do consumidor (emoções, prazer, sentimentos e outras), o produto é, assim, considerado hedônico por natureza. O consumo hedônico difere consideravelmente do consumo utilitário, 
Relações qualitativas de consumo: os serviços de hotelaria direcionados ao público homossexual

de Yákara Vasconcelos Pereira Leite, Valdemar Siqueira Filho e Juliana Pinheiro da Silva 258

por reconhecer os papéis das emoções no comportamento de consumo, por acreditar que o consumidor é dotado de sensibilidade com necessidade de diversão e prazer e pela significância dos simbolismos no consumo (ADDIS; HOLBROOK, 2001).

Hirschman e Holbrook (1982) concordam com Addis e Holbrook (2001, p. 92) ao acreditarem que os produtos, na perspectiva hedônica de consumo, são vistos como símbolos subjetivos, e não como entidades objetivas, ou seja, concebe-se o produto em sua representatividade e não pelo que ele realmente é. Os autores definem o consumo hedônico como as "facetas do comportamento do consumidor que relaciona os multi-sentidos, fantasias e aspectos emotivos com o produto", no que se refere aos sentidos múltiplos. São incluídos os aromas, os sons, o paladar, as imagens visuais e as impressões táteis. Existem, de fato, "muitos produtos que provocam insinuações que devem ser vistas, ouvidas, provadas, sentidas ou cheiradas" (HIRSCHMAN; HOLBROOK, 1982) em diversas situações de consumo, tais como comer em um restaurante. Nesse caso, esses canais sensoriais podem operar ao mesmo tempo. Parece-nos difícil aceitar a separação entre produtos utilitários e hedônicos, pois, reconhecendo que o homem está no mundo mediado pela linguagem, Peirce (1990) afirma que esta divisão não ocorreria, mas, pelo contrário, estas relações estariam mescladas entre si. Assim, podemos concluir que um hotel é ao mesmo tempo, um meio utilitário de abrigo e de status.

Cabe indicar também que a perspectiva estética do consumidor muda constantemente, e que tantos os serviços como os objetos passam rapidamente de um estado de beleza para outro de não beleza. A própria idealização de um lugar de paz, como de um espaço aconchegante que acolheria totalmente os desejos é por natureza uma idéia kischt de consumo. Não existe este lugar para um consumidor com um bom repertório cultural, mas, mesmo para aqueles que estivessem primeiramente em uma dimensão kischt, esta situação se mostra passageira, pois a insatisfação humana leva ao esquecimento determinados hábitos. Neste sentido, "o mau gosto" tende a ser apenas um estado de passagem entre o crescimento cultural dos consumidores.

Com relação ao encontro de serviço, ou seja, "a integração diádica que ocorre com os prestadores de serviço e os clientes", é considerado o ponto de partida nas avaliações do serviço pelos clientes (SAURA et al., 2005, p.50). As experiências de consumo nos serviços são, portanto, o resultado dessas interações entre "as organizações, os sistemas/processos relacionados, os funcionários e os consumidores" (BITNER et al., 1997, p.193). As experiências de consumo são criadas, moderadas e mediadas pelas emoções, que são um estado mental que surge a partir de avaliações de um acontecimento ou pensamento e podem 
Relações qualitativas de consumo: os serviços de hotelaria direcionados ao público homossexual

de Yákara Vasconcelos Pereira Leite, Valdemar Siqueira Filho e Juliana Pinheiro da Silva 259

gerar ações específicas, dependendo da natureza e dos pensamentos do indivíduo (GUTIÉRREZ, 2004).

Assim sendo, observa-se que os esforços a fim de criar conexões emocionais com os consumidores por meio do planejamento eficaz dos elementos tangíveis e intangíveis dos serviços têm alcançado maior relevância por parte das empresas da hospitalidade (PULLMAN; GROSS, 2003). Dube, Le Bel e Sears (2003, p.125) acreditam que é possível administrar diferentes elementos objetivos, tais como o ambiente físico, recursos humanos e comunicação, com a finalidade de "moldar as percepções dos hóspedes de modo que criem experiências prazerosas", pois, de acordo com os autores, os aspectos específicos dos hotéis funcionam como provedores de benefícios particulares que ficam guardados nas mentes dos hóspedes.

A importância do lado social na troca mútua do serviço foi considerada como relevante por Butcher (2005, p. 126), principalmente nos serviços da hospitalidade em que existe um grande contato entre os consumidores e os empregados. $\mathrm{O}$ autor definiu duas variáveis sociais (o conforto social e o valor social) capazes de influenciar o comportamento do consumidor e, consequentemente, os resultados do serviço, como as intenções de recompra. O conforto social foi definido como o "sentimento do consumidor de ansiedade ou relaxamento surgido da interação social com o empregado do serviço". Os sentimentos de conforto surgem a partir dos comportamentos dos outros no local, portanto, dentro das interações do serviço, são muitas vezes dependentes das ações dos funcionários da hospitalidade. A segunda variável, o valor social, diz respeito ao sentimento de valoração e importância demonstrado pelos prestadores de serviços aos seus clientes na realização do serviço (BUTCHER, 2005). Por esse motivo, Castelli (2001) considera que o elemento humano é um fator fundamental na indústria da hospitalidade.

Para Berry, Carbone e Haeckel (2002, p. 86), a experiência de consumo é considerada completa, ou "total", quando existe uma composição de todas as evidências de experiências. Os produtos e serviços oferecem uma gama de evidências de experiências que vão desde elementos físicos do ambiente até os funcionários, por meio de seus gestos, comentários, vestimenta e tons de voz. As evidências da experiência levam mensagens sugestivas para os consumidores e são dispostas em duas categorias.

A primeira categoria trata do funcionamento do produto ou serviço, que pode ser aplicado aos hotéis quando todos os aparelhos eletrônicos dentro do apartamento funcionam normalmente. A segunda categoria é constituída pelas emoções, incluindo os "cheiros, sons, paladares e texturas dos produtos e serviços, bem como o ambiente no qual são oferecidos". 
Relações qualitativas de consumo: os serviços de hotelaria direcionados ao público homossexual

de Yákara Vasconcelos Pereira Leite, Valdemar Siqueira Filho e Juliana Pinheiro da Silva 260

Os autores subdividiram a segunda categoria em dois tipos classificatórios de evidências, o tipo "mecânico", que diz respeito às evidências transmitidas por objetos materiais, e o tipo "humano", que são as evidências emitidas pelas pessoas envolvidas no processo do serviço. É o conjunto das evidências funcionais e emocionais da experiência que fará com que o consumidor decida se irá ou não comprar o produto ou serviço (BERRY; CARBONE; HAECKEL, 2002).

A fim de explicar como o processo da experiência na hospitalidade se realiza e é construída, Knutson e Beck (2003, p. 30) elaboraram um modelo teórico dividido em três partes específicas. A primeira parte do modelo é constituída pelo estágio da "pré-experiência" do consumo, o qual engloba as expectativas criadas pela marca, atividades promocionais, campanhas publicitárias e pelas memórias pessoais armazenadas em uma experiência anterior. As expectativas de um produto ou serviço são muito importantes no momento do consumo, pois elas podem afetar "o valor, o nível de engajamento, ligação emocional, grau de participação e a quantidade de estímulos de uma experiência”. A segunda parte foi considerada o "coração" do modelo e representa todas as experiências realizadas em tempo real nos encontros de serviço. Na hotelaria essa parte do modelo está relacionada com todos os estágios por que os hóspedes passam, incluindo o momento da realização da reserva do hotel, os procedimentos do check-in, estada e o check-out. Enfatiza-se que o grau de acessibilidade do serviço pode afetar o valor da experiência percebido pelos clientes. A acessibilidade dentro das experiências de consumo se refere ao custo, à entrega e à disponibilidade do serviço no momento em que o consumidor desejar adquiri-lo. A terceira parte do modelo é composta pela "pós-experiência", que se trata das percepções pessoais dos hóspedes em relação à experiência, o valor e a satisfação que eles atribuem à experiência. É também na terceira parte do modelo em que os atores incluem as reclamações dos clientes e suas resoluções por meio de um feedback após o consumo, para, então, concluir todo o processo da experiência de consumo (KNUTSON; BECK, 2003).

\subsection{Comportamento de consumo homossexual}

Segundo Kotler e Armstrong (1999, p. 97), as aquisições de bens e serviços "são altamente influenciadas pelas características culturais, sociais, pessoais e psicológicas" do consumidor. Por esse motivo, a segmentação tem sido considerada uma das atividades principais do marketing, pois, quando uma demanda é agrupada em segmentos específicos, o 
Relações qualitativas de consumo: os serviços de hotelaria direcionados ao público homossexual

de Yákara Vasconcelos Pereira Leite, Valdemar Siqueira Filho e Juliana Pinheiro da Silva 261

profissional de marketing pode construir um mercado de produtos ou serviços específicos para atender as necessidades e os desejos particulares do segmento (FUGATE, 1993).

Ao analisar o público gay, Fugate (1993) percebeu que esse segmento poderia ser identificado por meio de seu estilo de vida, porém, esse público não deveria merecer esforços de marketing já que o autor não considerou esse segmento como viável, de acordo com os critérios utilizados em sua pesquisa (identificação, acessibilidade, tamanho populacional e estabilidade). Peñazola (1996, p. 22) discorda dessa afirmação, ao considerar que a categorização apresentada por Fugate (1993) "reduz a cultura gay e lésbica à sexualidade, mesmo passando por cima das variações existentes nas atividades, interesses e opiniões entre lésbicas e homens gays, isto é, desconsiderando as complexidades de suas vidas.

Com a participação de movimentos sociais, os gays têm desenvolvido uma consciência sobre eles mesmos que é fruto dos interesses comuns e das experiências de exclusão, mobilização e maus tratos sofridos pela sociedade dominante (PENÃZOLA, 1996). Por essa razão, os homossexuais foram classificados no mercado como uma subcultura de consumo, uma vez que a subcultura de consumo é "um fenômeno socialmente construído" (NUNAN; JABLONSKI, 2002) e agrupa indivíduos com estilo de vida, significados, valores, atitudes e crenças semelhantes e opostos à cultura dominante (KATES, 1998; NUNAN, 2003). Ao serem agrupados em uma subcultura de consumo, há facilidade em serem identificados e incluídos em padrões de consumo por meio das dimensões distintas de identidade, práticas sociais e formações de comunidades (PENÃZOLA, 1996). Assim, uma subcultura é constituída por "significados, códigos, linguagem, normas, valores, costumes, pontos de encontro, atividades, instituições (estrutura de apoio material e psicológico) e tradições" (NUNAN; JABLONSKI, 2002, p. 21).

Alguns dos estudos mais profundos da literatura sobre o comportamento de consumo dos homossexuais foram realizados por pesquisadores estrangeiros em seus respectivos países de origem (DELOZUIER; RODRIGUE, 1996; HASLOP; HILL; SCHMIDT, 1998; HUGHES, 2002; KATES, 1998, 2002; LUKENBILL, 1999). Porém, apesar dessas pesquisas terem sido realizadas no exterior, Nunan (2003) afirma que o comportamento de consumo dos homossexuais estrangeiros é semelhante ao comportamento de consumo dos homossexuais brasileiros. Esta proposição pode valor parciamente considernando que cultura gay segue padrões mudializados de peformnace. Por outro lado, ele nos parece incorreta, no sentido de que a cultura de cada nação ou mesmo região, não possa imprimir identidade própria a suas realidades culturais específicas. Dessa forma, soa estranho pensar que gays europeus, latinos, 
Relações qualitativas de consumo: os serviços de hotelaria direcionados ao público homossexual

de Yákara Vasconcelos Pereira Leite, Valdemar Siqueira Filho e Juliana Pinheiro da Silva 262

asiáticos, e assim por diante, não poderiam ser diferenciados, mas talvez essas diferenças não pesem na oferta de um consumo mudializado.

A justificativa para a proposição destes autores é que o comportamento de consumo do homossexual foi considerado por Kates (1998, p. 81) como simbólico por natureza e, por esse motivo, os significados originais dessa subcultura são investidos em produtos e serviços. Dessa forma, os produtos e serviços assumem uma importante função de "criação e manutenção do conceito próprio, da política e da comunidade". Peirce (1990) afirma que o homem é um ser simbólico por natureza, portanto isto não seria um atributo da homessexualidade, mas sim a única forma que o ser humano tem para se relacionar com a natureza, ou seja, pela linguagem com mediadora do mundo.

Os homossexuais do gênero masculino foram considerados por Kates (1998) como muito materialistas e ambiciosos, no que se refere às roupas, aos tratamentos estéticos e aos móveis. Tal fato também foi constatado por Nunan (2003), ao afirmar que, independentemente da classe social, os homossexuais valorizam a imagem, a aparência e a moda e, além disso, estão voltados à informação e ao lazer. Eles procuram informações sobre o que está acontecendo no mundo e na moda e nos relacionamentos pessoais. O estereótipo sobre heterossexual não apresentar cuidados com a aparência não se confirma. Partindo do estudo da linguagem, todos os homens fazem uso de um padrão estético que orienta suas escolhas.

Sobre o turismo de homossexuais, Hughes (2002) explica que existe maior disposição para viagens por parte dos gays do sexo masculino, relacionadas ao interesse por atividades culturais e por turismo urbano. Ou seja, os destinos com infra-estrutura, que possuam feriados em seu calendário e não tenham atitudes homofóbicas, são preferidos pela clientela dos homossexuais. As principais motivações pessoais dos homossexuais masculinos em viajar foram identificadas em um estudo realizado por Clift e Forrest (1999, apud Hughes 2002). Nessa pesquisa, foi constatado que é dada maior importância ao descanso, relaxamento, conforto e boa comida pelos homossexuais masculinos no momento em que estão planejando suas viagens. Além disso, os entrevistados consideraram a interação social com outros homossexuais e acesso à cultura e pontos de venda gay como fatores relevantes em sua decisão (CLIFT; FORREST, 1999 apud HUGHES, 2002).

Segundo Lukenbill (1999, p.52), os gays "viajam muito, tanto domesticamente quanto para o exterior", "com bastante frequência" (NUNAN, 2003, p. 161) e tendem a optar por destino onde "existe maior liberdade sexual ou uma comunidade gay estabelecida" (NUNAN, 2003, p. 161). O fato de realizarem várias viagens a lazer está intimamente ligado ao alto 
Relações qualitativas de consumo: os serviços de hotelaria direcionados ao público homossexual

de Yákara Vasconcelos Pereira Leite, Valdemar Siqueira Filho e Juliana Pinheiro da Silva 263

nível de estresse que os homossexuais vivem no seu dia-a-dia (LUKENBILL, 1999). Em sua pesquisa, Lukenbill (1999) constatou que 85\% dos homossexuais masculinos sentem a necessidade de encontrar maneiras de reduzir o estresse e, por esse motivo, o turismo é visto por eles como "uma forma de reduzir elevados níveis de estresse" sofridos em seu cotidiano (NUNAN, 2003, 161). Os homossexuais têm empreendido viagens como uma maneira de se sentirem livres da heterossexualidade e, por esse motivo, eles têm buscado lugares em que podem, de uma maneira ou de outra, "se descobrir ou ser eles mesmos a partir do desempenho do gênero e papéis sexuais" (WAITT; MARKWELL, 2006, p. 4). Concordando sobre certos aspectos sobre o problema do estresse, cabe ressaltar que qualquer pessoa que vive no mercado de trabalho responde a um alto nível de tensão, de competitividade e de inúmeros preconceitos, de gênero, de cor, de pertencimento a outras regiões, principalmente aqui no Brasil quando se trata de pessoas vindas do nordeste do país. Portanto parece-nos que estas análises absolutizam processos que seriam muito mais complexos e atingiriam todas as pessoas.

Outra característica dos consumidores gays é a de atribuir um significado especial e desprender maiores esforços em consumir produtos e serviços oferecidos por empresas administradas por homossexuais, a fim de promoverem conexões simbólicas com a comunidade gay, mesmo quando o produto ou o serviço não é considerado de alta qualidade (KATES, 1998). Os bares, restaurantes e clubes voltados para o público homossexual também provocam reações internas importantes para o entendimento do comportamento do consumidor gay. É nesses espaços que os homossexuais mantêm sua rede de amizades, interagem socialmente com os outros e podem expressar livremente sua identidade cultural e sexual (HUGHES, 2002). A importância do ambiente de serviços de lazer como fator de grande influência na experiência de consumo homossexual foi estudada por Haslop, Hill e Schimidt (1998).

Em sua pesquisa realizada em bares gays, na cidade de Manchester, nos Estados Unidos, Haslop, Hill e Schimidt (1998, p. 323) constaram que os homossexuais que experienciavam os serviços oferecidos nos bares gays da cidade tiveram sentimentos de liberdade, liberação, segurança e de participação social. Duas influências-chave do ambiente de serviços que atraíram e agradaram os consumidores gays foram a música e a atmosfera do local. Embora tenha sido a música considerada uma importante influência no consumo, não foi constatado nenhum tipo específico de música que exercesse maior preferência entre os homossexuais; o que existe, no entanto, é a preferência por determinadas músicas dependendo da situação. Um dos entrevistados, por exemplo, afirmou preferir músicas com volume mais 
Relações qualitativas de consumo: os serviços de hotelaria direcionados ao público homossexual

de Yákara Vasconcelos Pereira Leite, Valdemar Siqueira Filho e Juliana Pinheiro da Silva 264

alto quando sai com outros amigos gays, contudo, essa preferência muda quando está acompanhado com seu parceiro para uma música de fundo. O outro fator que pode exercer influência no consumo gay, segundo o estudo, é a atmosfera. A atmosfera foi considerada pelos respondentes como uma "integração de todos os aspectos do ambiente", como a música, a decoração e os frequentadores do local. Cabe ressaltar que os melhores estabelecimentos comerciais, ou aqueles que mais conquistam a fidelidade de qualquer tipo de consumidor, oferecem serviços especiais, vinculados a qualidade, bom gostos e atendimento, portanto não seria apenas um fenômeno estudado por estes autores.

Haslop, Hill e Schimidt (1998) também encontraram os valores mais aparentes entre os consumidores homossexuais durante suas experiências em um ambiente de serviços, que vão ao encontro dos resultados identificados por Lukenbill (1999), que são a segurança, a oportunidade de poder se expressar, liberdade, comunidade, individualismo, hedonismo e diversidade. Percebe-se, assim, como "a subcultura de consumo ajuda o indivíduo a solucionar vários problemas que estão relacionados com a necessidade de liberdade, identidade, afiliação com outros" (KATES, 1998, p. 132).

Um estudo relevante na área de hospitalidade foi realizado por Poria (2006) e demonstra o estado da arte de estudo sobre a experiência de gays e lésbicas em hotéis. Segundo essa pesquisa, foi verificado que é importante para os homossexuais se sentirem bem-vindos e aceitos quando sua orientação sexual é conhecida. Por esse motivo, os participantes do estudo de Poria (2006) destacaram a sua satisfação quando os funcionários de hotéis alocam o casal de gays em apartamentos de cama de casal. Isso, para eles, tem um significado simbólico, pois é na alocação em apartamentos com cama de casal que eles percebem que sua orientação sexual é aceita no estabelecimento. De acordo com Poria (2006, p. 330), "quase todos os participantes disseram que gostariam de sentir que eles estão sendo servidos e tratados pelos funcionários do mesmo modo que os outros hóspedes". Outro aspecto encontrado nesse estudo é o valor que os homossexuais entrevistados deram à segurança do local para os gays, em geral, e ao horário do café da manhã mais prolongado.

Além das peculiaridades dos produtos e serviços, os gays investem em empresas que os respeitam como seres humanos dignos. Por isso, os empreendimentos que possuírem funcionários homossexuais, financiarem instituições que defendem diferentes assuntos relacionados com a vida dos homossexuais ou promoverem seus produtos ou serviços direcionados aos gays nos canais de comunicação, conquistarão o consumidor homossexual (KATES, 1998; LUKENBILL, 1999). Segundo Kates (1998), a melhor maneira de atingir o mercado homossexual é por meio do cultivo de uma relação comercial, de longo prazo e de 
Relações qualitativas de consumo: os serviços de hotelaria direcionados ao público homossexual

de Yákara Vasconcelos Pereira Leite, Valdemar Siqueira Filho e Juliana Pinheiro da Silva 265

benefícios mútuos com os gays. Essa relação precisa ser construída com confiança, com trabalho qualificado, não somente para o universo homossexual mas também para todos os clientes.

\section{METODOLOGIA}

Considerando as premissas da pesquisa qualitativa de "procurar descobrir e entender um fenômeno, um processo ou perspectivas e visões de mundo das pessoas envolvidas" (MERRIAM, 1998, p. 11), utilizou-se essa perspectiva na realização deste estudo.

Foram entrevistados homossexuais, do gênero masculino, residentes à cidade do Recife. A quantidade de sujeitos selecionados foi definida ao considerar a saturação de informações das categorias formadas tendo em vista o alcance da resposta a questão de pesquisa. Como critério de seleção desses sujeitos, optou-se por selecionar os que teriam algum curso superior completo ou em andamento. Além disso, foi relevante o fato de que os entrevistados se auto-definissem como gays, pois "o fato de um homossexual ser assumido tem grande influência em seu comportamento de consumo" (NUNAN, 2003, p. 202), além do que os entrevistados não se sentiriam constrangidos durante a coleta de dados.

A fim de selecionar os entrevistados, após a identificação do primeiro respondente, utilizou-se a técnica conhecida como snowball sampling (amostragem por "bola de neve"), na qual um participante da pesquisa é conhecido individualmente pelo pesquisador (NUNAN, 2003) e, posteriormente, o investigador solicita aos respondentes a indicação de outros sujeitos sociais que possam contribuir para a pesquisa (MCDANIEL; GATES, 2005). É importante salientar que "esse tipo de amostragem só funciona com populações cujos membros se conheçam entre si, a exemplo da comunidade gay" (NUNAN, 2003, p. 204).

Salienta-se que, diferentemente da perspectiva quantitativa, que trabalha com amostras maiores por buscar generalizações estatísticas, a abordagem qualitativa preocupa-se com o exame detalhado do fenômeno, selecionando, assim, menor número de pessoas para ter condições de aprofundar o estudo e alcançar alto nível de análise. Desse modo, quando as categorias que explicavam o fenômeno estudado emergiram com consistência, percebeu-se que o número de entrevistados já era suficiente (MERRIAM, 1998).

Por se tratar de estudo qualitativo, foi escolhida a entrevista semi-estruturada (GRESSLER, 2004; PATTON, 2001), como instrumento de coleta de dados por permitir o aprofundamento do tema pesquisado e por parecer mais adequada para que os aspectos do 
Relações qualitativas de consumo: os serviços de hotelaria direcionados ao público homossexual

de Yákara Vasconcelos Pereira Leite, Valdemar Siqueira Filho e Juliana Pinheiro da Silva 266

comportamento de consumo dos homossexuais pudessem ser descritos, compreendidos e interpretados (NUNAN, 2003).

Por essa técnica, cada um dos respondentes foi entrevistado uma vez, em ambientes variados, no período de um mês, entre agosto e setembro de 2006. Todas as entrevistas aconteceram na cidade do Recife, foram gravadas digitalmente e logo depois transcritas na íntegra. É importante mencionar que os entrevistados não estão identificados por seus próprios nomes com a finalidade de preservar a sua confidencialidade. Assim, foram utilizados nomes fictícios.

Por fim, tem-se a análise dos dados, levando-se em consideração a perspectiva qualitativa. Nesse âmbito, foram examinados os relatos dos respondentes, tendo sido interpretados todos os dados, considerando-se a fundamentação teórica que embasou este trabalho. Com isso, identificaram-se categorias, que emergiram dos relatos dos entrevistados, que respondessem ao problema de pesquisa.

\section{DISCUSSÃO DOS RESULTADOS}

Nesta seção serão discutidos os resultados com a finalidade de responder à pergunta de pesquisa: Quais são as respostas internas dos consumidores gays entrevistados durante a experiência de consumo nos hotéis? Nota-se que, dentre as reações internas propostas por Bitner (1992), as respostas emocionais e fisiológicas foram as que mais se destacaram nesta pesquisa. As respostas emocionais, dos entrevistados, identificadas foram a sensação de liberdade, de privacidade, de tranquilidade e de paz, enquanto que as respostas fisiológicas dos entrevistados consistiram no conforto e no relaxamento que o ambiente de hotéis oferece.

\subsection{Respostas emocionais}

Segundo Waitt e Markwell (2006), para os homossexuais, viajar é uma forma de mecanismo para escapar da clausura em que vivem no seu dia-a-dia e, por esse motivo, percebem que o tempo em que ficam hospedados em hotéis é uma maneira de se sentirem livres (PORIA, 2006). Isso é confirmado a partir da afirmação de João da Costa. Ele explica que "Era, era uma questão sair daqui e ficar lá tranquilo, sem ter a responsabilidade de estar em sua cidade e ser quem você é dentro da sua cidade". Esse fato está aliado à preferência dos homossexuais entrevistados em viajar para João Pessoa, na Paraíba, pois a distância entre Recife não é muito grande. João da Costa apresenta os motivos que fizeram com que ele 
Relações qualitativas de consumo: os serviços de hotelaria direcionados ao público homossexual

de Yákara Vasconcelos Pereira Leite, Valdemar Siqueira Filho e Juliana Pinheiro da Silva 267

viajasse para João Pessoa e retornasse à cidade e, consequentemente, ao mesmo hotel: "teve uma questão que era perto e a gente poderia ter mais privacidade".

Segundo Apadurai (1990), existe uma necessidade do ponto de vista de uma pessoa cosmopolita passar despercebida entre os lugares que visita, pois isto exige certa competência, qual seja a de saber se apropriar dos elementos culturais e simbólicos que orientam os lugares da cidade, diferentemente do turista que, por não ter este tipo de competência, é facilmente reconhecido pelos moradores do local. Neste sentido o anonimato pode significar por um lado o exercício de uma habilidade, como também o descanso do papel social que aprisiona o comportamento do cidadão. A questão colocada sobre o anonimato deve ser relativizada neste caso, pois a proximidade entre as cidades é impeditiva para este tipo de expectativa e deve-se levar em conta que acasos sempre ocorrem e todos estamos sujeitos a encontrar conhecidos em toda a parte do mundo.

Além de fugir da cidade de origem, é nos hotéis que os homossexuais podem ter momentos de privacidade com seus parceiros. João da Silva também afirma que é importante a postura do funcionário do hotel em relação à privacidade e descreve como os funcionários de um hotel em que se hospedou se comportavam e, por esse motivo, gostou muito: "eles não invadem a sua privacidade, o que importa para ele é que você se sinta bem ao se hospedar ali, mas eles não querem mais saber de você além disso". Esta indicação reforça nosso ponto de vista sobre a perspectiva da privacidade como um bem que buscamos para viver nossos momentos de lazer.

Além da privacidade, os sentimentos de paz e tranquilidade se sobressaíram quando os entrevistados relataram as experiências positivas que tiveram em suas hospedagens em hotéis. Para João da Costa, por exemplo, a experiência no restaurante de um hotel em que se hospedou foi bastante significativa por passar uma atmosfera de tranquilidade e paz, e descreve como era o restaurante e como se sentiu:

O café da manhã era nessa parte do hotel que era tipo um janelão de vidro como se fosse uma parede de frente pro mar, a água do mar batia e tinha umas pedras em baixo. A gente tomava o café nessa parte. Olhava a paisagem, dava aquela sensação de paz, parecia que estava na praia e isso dentro da cidade.

João da Silva também declara as razões pelas quais gostou do tipo de decoração de um restaurante de hotel: "Porque é singelo, é tranquilo, descansa a vista, porque eles prezam muito pelo branco, aquelas coisas orientais, aquelas coisas muito limpas, muito organizadas e isso realmente chama(m) a atenção". Esse depoimento de João da Silva corrobora o estudo de 
Relações qualitativas de consumo: os serviços de hotelaria direcionados ao público homossexual

de Yákara Vasconcelos Pereira Leite, Valdemar Siqueira Filho e Juliana Pinheiro da Silva 268

Lukenbill (1999), que afirma que a sensação de relaxamento é importante para os homossexuais entre trinta e quarenta anos.

Como foi percebido, não é somente para essa faixa de idade que o lazer e o relaxamento são importantes, pois a sensação de tranquilidade foi identificada como fundamental para todos os homossexuais entrevistados. Essa constatação pôde ser confirmada a partir do depoimento de Eduardo Assis: "Eu gosto de um ambiente harmonioso, calmo e tranquilo". A busca da tranquilidade e paz pelos entrevistados confirma o que foi apresentado nos estudos de Nunan (2003) e Lukenbill (1999), os quais afirmam que esse fenômeno está intimamente associado com os elevados níveis de estresse produzido pela vida cotidiana. Mais uma característica de destaque é a necessidade de interação social que os homossexuais têm, principalmente quando estão em companhia de heterossexuais. Como foi mostrado anteriormente, os gays que estão em companhia de pais ou amigos heterossexuais preferem ficar no lobby ou nas áreas sociais dos hotéis. São nesses locais que os homossexuais entrevistados podem ter algum tipo de contato com outras pessoas hospedadas ou com os próprios funcionários do hotel.

João da Costa, por exemplo, gostava de ficar no lobby do hotel e explica suas razões: “Aí eu ficava meio que circulando nessa área, ficava chegando gente, era bem movimentado". Já Eduardo Assis acha positivo interagir com os funcionários do hotel durante a hospedagem e explica o que é importante em suas hospedagens: "quando você consegue se afeiçoar por algum funcionário do hotel, alguém que você fica brincando quando você está num grupo grande aí você consegue se afeiçoar também pelo hotel”.

Diante disso, acredita-se que esta pesquisa ofereça, dentre outras, uma contribuição significativa tanto para a literatura quanto para a prática, ao observar que existe uma necessidade, por parte dos gays acompanhados por heterossexuais, de interagir com outras pessoas no hotel, enquanto que os homossexuais com o seu parceiro desejam aproveitar o momento a sós.

Esta questão precisa, entretanto, ser relativizada, pois, dependendo do casal, a resposta apresenta variações, seja pelo tempo em que eles estão juntos, influenciando assim a necessidade de privacidade, ou mesmo pelas características de sociabilidade que cada pessoa apresenta como performance social.

\subsection{Respostas fisiológicas}


Relações qualitativas de consumo: os serviços de hotelaria direcionados ao público homossexual

de Yákara Vasconcelos Pereira Leite, Valdemar Siqueira Filho e Juliana Pinheiro da Silva

Outro ponto que merece ênfase é o valor da sensação de conforto que os homossexuais atribuem às experiências positivas que vivenciaram, sendo esse um dos motivos para retornar ao local, permanecer mais tempo ou considerar o serviço ou produto de qualidade. Segundo a pesquisa realizada por Kates (1998), os homossexuais inferem uma qualidade superior quando a experiência dos serviços proporciona conforto e este é um dos fatores mais importantes no planejamento de suas viagens (CLIFT; FORREST, 1999 apud HUGHES, 2002). Isso vai em concordância com as declarações dos homossexuais entrevistados nesta pesquisa. Antônio Cavalcanti, por exemplo, afirma que: "eu gosto de me sentir bem, me sentir confortável". O mesmo foi relatado por Gabriel Montenegro, quando questionado sobre o que o faz sentir-se bem nos hotéis: "hotel com quarto bonito, confortável, que você fica deitado [...]". Pedro Araújo afirma categoricamente que "o quarto tem que ser confortável [...]”.

De acordo com João da Silva, o:

[...] atendimento personalizado, educação, a postura, a prontidão em atender, a questão da própria delicadeza com a situação, a discrição para mim é fundamental. Então, o máximo de profissionalismo e o mínimo de intimidade porque eu acho que a relação é profissional a não ser que o próprio cliente permita intimidade e ainda assim acho que, como profissional, você tem que manter sua distância, porque é assim que tem que funcionar, não tem que misturar muito as áreas. O que eu costumo dizer é que no Nordeste, por exemplo, você chega em uma pousada e o dono já quer ser seu íntimo, comigo você já perde seus pontos aí, eu acho que a postura é essa, você ri com o cliente, trata bem, etc. e tal, mas você é cortado, você é polido, então, isso conta muito em um hotel.

Esse depoimento também está em consonância com o estudo de Butcher (2005), o qual advoga que o conforto social deriva do comportamento dos funcionários no ambiente da hospitalidade, podendo fazer com que o cliente se sinta relaxado ou ansioso durante a interação com o funcionário. No caso de João da Silva, um bom atendimento, ou seja, uma interação positiva com os funcionários do hotel pode fazer com que ele continue hospedado no mesmo local por mais tempo ou volte a se hospedar nele por causa da sensação de conforto e relaxamento que essa interação pode proporcionar.

Para os homossexuais acompanhados pelos seus parceiros, no entanto, as áreas sociais dos hotéis, especialmente a piscina, são um local para relaxar. Gabriel Montenegro, por exemplo, gostou das piscinas de um hotel devido à sua variedade e à sensação de relaxamento: "piscina com cachoeira, piscina com não sei o que, piscina com massagem, piscina com água morna. Era um hotel que você faz questão só pelo hotel, não faz nem questão de sair, lá você relaxa [...]”. Antônio Cavalcanti, que acompanhava Gabriel Montenegro nesse hotel, também ressaltou a existência de uma piscina aquecida e complementa: “[...] tinha piscina aquecida, então, tanto faz se está no inverno, chega aquela 
Relações qualitativas de consumo: os serviços de hotelaria direcionados ao público homossexual

de Yákara Vasconcelos Pereira Leite, Valdemar Siqueira Filho e Juliana Pinheiro da Silva 270

hora de manhã que você está com medo de entrar na água. Outra coisa, eu gosto de nadar. Um hotel que tenha uma piscina que eu possa nadar, eu gosto de ficar nadando".

Esses resultados estão alinhados com aquilo que Clift e Forrest (1999), apud Hughes (2002), ressaltaram em sua pesquisa. Eles constataram que o descanso e o relaxamento são considerados relevantes para os homossexuais, quando estão planejando alguma viagem.

\section{CONSIDERAÇÕES FINAIS}

Pôde-se, portanto, obter alguma compreensão dos sentimentos dos homossexuais entrevistados por meio da investigação de suas experiências de consumo, ao identificar suas respostas internas emitidas. Essas respostas são o sentimento de liberdade, tranquilidade, sensação de paz, privacidade, conforto e relaxamento. O conhecimento desses sentimentos e sensações possibilita compreender melhor os significados internos que os homossexuais levam consigo, podendo, assim, ser utilizado a fim de promover uma relação interpessoal e (por que não?) entre pessoas e organizações empresariais equivalentes.

Como foi mencionado anteriormente, é durante suas hospedagens em hotéis que os homossexuais se sentem livres da cultura predominantemente heterossexual (ou livres da homogeneidade), pois é nos apartamentos dos hotéis que eles podem se sentir livres para expressar suas sexualidades e aproveitar o momento de mais intimidade com seus parceiros.

Observou-se também que, pelo fato de estarem hospedados em hotéis, eles sentem privacidade para desfrutarem de momentos românticos com seus parceiros. Por isso, a necessidade de se sentirem confortáveis no apartamento de hotel também é importante, já que é nesse local que eles podem ser quem eles quiserem, sem se preocupar com a reação das outras pessoas da sociedade. A sensação de relaxamento pode ser proporcionada quando existe uma interação positiva com os funcionários do hotel, provocando, assim, um conforto social.

O fato de serem "livres" leva-os a viajar, principalmente para cidades próximas do Recife. A cidade de João Pessoa, por exemplo, foi um dos lugares mais citados pelos entrevistados e é vista como uma forma de refúgio mais acessível por ser próxima e dispor de hotéis com algumas características preferidas por eles.

A sensação de tranquilidade é uma das reações internas mais relevantes, para que o homossexual se comporte de maneira positiva. Os gays, de modo geral, se sentem estressados e oprimidos no seu dia-a-dia devido à orientação sexual que escolheram para viver em uma sociedade predominantemente heterossexual (LUKENBILL, 1999; NUNAN, 2003). Por isso, 
Relações qualitativas de consumo: os serviços de hotelaria direcionados ao público homossexual

de Yákara Vasconcelos Pereira Leite, Valdemar Siqueira Filho e Juliana Pinheiro da Silva 271

quando viajam, as sensações mais memoráveis são aquelas que os fazem sentir-se tranquilos, em paz, relaxados e sem preocupações exteriores.

Percebeu-se, ainda, que as experiências dos homossexuais estão intimamente relacionadas com os estímulos dos canais sensoriais (visão, audição, olfato e tato), além dos sentimentos provocados pelo ambiente. Esses dois fatores fazem parte dos cinco módulos experienciais estratégicos, que são a sensação, o sentimento, o pensamento, a ação e a identificação, propostos por Schmitt (2002).

Desse modo, acredita-se que, tanto na perspectiva científica quanto na da prática empresarial, possam ser utilizadas essas informações para o desenvolvimento desses campos de atuação. Este estudo tem caráter exploratório e indica-se a continuação de investigações sobre essa temática. Considera-se que esses dados podem fornecer uma compreensão do segmento homossexual, mas também de um público mais exigente, pois nossa pesquisa teve como público pessoas com nível universitário, indicando assim a necessidade de estabelecer padrões de qualidade nos serviços que atendam a um consumidor mais exigente e que tende a crescer muito neste país.

\section{REFERÊNCIAS BIBLIOGRÁFICAS}

ADDIS, Michela; HOLBROOK, Morris B. On the conceptual link between mass customization and experiencial consumption: an explosion of subjective. Journal of Consumer Behavior, v. 1, n. 1, p. 50-66, 2001.

APPADURAI, Arjun. "Disjunção e diferença na economia cultural global”. In: FEATHERSTONE, Mike. (Org.). Cultura global: nacionalismo, globalização $e$ modernidade. Rio de Janeiro, Vozes, 1990.

BAKHTIN, Mikhail M. Marxismo e filosofia da linguagem. São Paulo, Hucitec, 1986.

BERRY, Leonard L.; CARBONE, Lewis P.; HAECKEL, Stephan H. Managing the total customer experience. MIT Sloan Management Review, v. 43, n. 3, p. 85-89, 2002.

BITNER, Mary Jo; FARANDA, William T.; HUBBERT, Amy R.; ZEITHAML, Valarie A. Customer contributions and roles in service delivery. International Journal of Service Industry Management, v. 8, n. 3, p. 193, 1997.

BUTCHER, Ken. Differential impact of social influence in hospitality encounter. International Journal of Contemporary Hospitality Management, v. 17, n. 2, p. 125$135,2005$. 
Relações qualitativas de consumo: os serviços de hotelaria direcionados ao público homossexual

de Yákara Vasconcelos Pereira Leite, Valdemar Siqueira Filho e Juliana Pinheiro da Silva 272

DUBE, Laurette; LE BEL, Jordan; SEARS, Donna. From Customer Value to Engineering Pleasurable Experiences in Real Life and Online. Cornell Hotel and Restaurant Administration Quarterly, v. 44, n. 5/6, p. 124-131, 2003.

FUGATE, Douglas L. Evaluating the Us Male Homosexual and Lesbian Population as a Viable Target Market Segment. Journal of Consumer Marketing, v. 10, n. 4, p. 46-57, 1993.

GRESSLER, Lori Alice. Introdução à pesquisa: projetos e relatórios. São Paulo, Loyola, 2004.

HASLOP, Craig; HILL, Helene; SCHIMIDT, Ruth A. The gay Lifestyle: Spaces for a Subculture of Consumption. Marketing Intelligence \& Planning. v. 16, n. 5, p. 318326, 1998.

HIRSCHMAN, Elizabeth C.; HOLBROOK, Morris B. Hedonic consumption: emerging concepts, methods and propositions. Journal of Marketing, v.46, p.92-101, 1982.

HOLANDA, Sergio B. Raizes do Brasil. São Paulo, 2006.

HUGHES, Howard L. Marketing gay tourism in Manchester: new market for urban tourism or destruction of "gay space"? Journal of Vacation Marketing, v. 9, n. 2, p. 152-163, 2002.

KATES, Steven M. Twenty million new customers! Understanding gay men's consumer behavior. New York, Harrington Park Press, 1998.

KNUTSON, Bonnie J. ; BECK, Jeffrey A. Identifying the dimentions of the experience construct: development of the model. Journal of Quality Assurance in Hospitality \& Tourism, v. 4, n. 3/4, p. 23-35, 2003.

KOTLER, P. Administração de Marketing. São Paulo, Prentice Hall, 2000.

KOTLER, Philip; ARMSTRONG, Gary. Princípios de Marketing. Rio de Janeiro: LTC, 1999.

LOTMAN, IURI M. Sobre o problema da tipologia da cultura, in: SCHNAIDERMAN, Bóris. Semiótica da Cultura. São Paulo, Perspectiva, 1979.

LUKENBILL, Grant. Untold millions: secret truths about marketing to gay and lesbian consumers. New York, Harrington Park Press, 1999.

MCDANIEL, Carl; GATES, Roger. Pesquisa de marketing. São Paulo: THOMSON, 2005.

MERRIAM, Sharan B. Qualitative research and case study applications in education. San Francisco, Jossey-Bass, 1998. 
Relações qualitativas de consumo: os serviços de hotelaria direcionados ao público homossexual

de Yákara Vasconcelos Pereira Leite, Valdemar Siqueira Filho e Juliana Pinheiro da Silva 273

MORAES, Claudia Corrêa de Almeida. Turismo: Segmentação de Marcado: um estudo introdutório. 13 - 33p. In: ANSARAH, Marilia Gomes dos Reis (Org.). Turismo: segmentação de mercado. São Paulo, Futura, 2000.

MORIN, Edgar. A cabeça bem feita: repensar a reforma, reformar o pensamento. Rio de Janeiro, Bertrand Brasil, 2006.

NEWMAN, P. J.; NELSON, M. R. Mainstream legitimization of homosexual men through valentine's day gift-giving and consumption ritual. In: WARDLOW, D. L. (Org.). Gays, lesbians and consumer behavior: theory, practice and research issues in marketing. New York, Harrington Park Press, p. 57-69, 1996.

NUNAN, Adriana; JABLONSKI, Bernardo. Homossexualidade e preconceito: aspectos da subcultura homossexual no Rio de Janeiro. Arquivos Brasileiros de Psicologia, v. 54, n.1, p. 21-32, 2002.

NUNAN, Adriana. Homossexualidade: do preconceito aos padrões de consumo. Rio de Janeiro, Caravansarai, 2003.

PATTON, Michael Quinn. Qualitative research and evaluation methods. California, Sage Publication, 2001.

PEIRCE, Charles S. Semiótica. São Paulo, Perspectiva, 1990.

PENÃZOLA, L. We're here, we're queer, and we're going shopping! A critical perspective on the accommodation of gays and lesbians in the U.S. marketplace. In: WARDLOW, D. L. (org.). Gays, lesbians and consumer behavior: theory, practice and research issues in marketing. New York, Harrington Park Press, 1996, p. 9-41.

PEREIRA, Bill Nunes; AYROSA, Eduardo André Texeira; OJIMA, Sayuri. Consumo entre gays: compreendendo a construção da identidade homossexual através do consumo. In: ENCONTRO ANUAL DA ANPAD, 29, Brasília, 2005. Anais... Brasília: ANPAD, 2005.

PINE, J.; GILMORE, J.H. Welcome to the experience economy. Havard Business Review, v. 76, n. 4, p.97-105, 1998.

PIGNATARI, Décio. Contracomunicação. Cotia/SP, Ateliê Editorial, 2004.

PINHEIRO, Amálio. Aquém da identidade e da oposição: Formas na cultura mestiça. Piracicaba/SP, 1995.

PORIA, Yaniv. Assessing Gay Men and Lesbian Women's Hotel Experiences: An Exploratory Study of Sexual Orientation in the Travel Industry. Journal of Travel Research, v. 44, n. 3, p. 327-334, 2006. 
Relações qualitativas de consumo: os serviços de hotelaria direcionados ao público homossexual

de Yákara Vasconcelos Pereira Leite, Valdemar Siqueira Filho e Juliana Pinheiro da Silva 274

PULLMAN, Madeleine E.; GROSS, Michael A. Welcome to your experience: where you can check out anytime you'd like, but you can never leave. Journal of Business and Management, v. 9, n.3, 2003.

SAURA, Irene Gil; PÉREZ, Manuel Sánchez; CONTRÍ, Gloria Berenguer; GONZÁLEZGALLARDA, Martina. Encuentro de servicio, valor percibido y satisfacción del cliente en la relación entre empresas. Cuadernos de Estudios Empresaeiales, n. 15, p. 47-72, 2005.

SCHMITT, Bernd H. Marketing experimental. São Paulo, Nobel, 2002.

SCHMITT, Bernd H.; SIMONSON, A. A Estética do Marketing. São Paulo, Nobel, 2000.

SERRES, Michel. Terceiro Instruído. Lisboa, Instituto Piaget, 2001.

WAITT, Gordon; MARKWELL, Kevin. Gay tourism: culture and context. New York, Haworth Hospitality Press, 2006.

Artigo Recebido: 20/11/2010

Artigo Aprovado: 10/12/2010 